\title{
Illustrations
}

\section{TABLES IN TEXT}

1 Growth of Scientific Research Institutes of NTO

VSNKh, 1923-1930

62

2 Scientific Institutes Under Glavnauka RSFSR, 1922-1927

3 Structure of Leningrad Physico-Technical Institute, 1924

4 Organization of Leningrad Physico-Technical Laboratory, 1928-1929

5 Attendance of RAF Congresses, 1919-1930

138

6 Scientific Research Institutes and Personnel of Narkomtiazhprom, 1931-1935

7 Organization of the Physics Association of Narkomtiazhprom

8 Organization of Leningrad Physico-Technical Institute, 1931

9 Communist "Scientific Workers," by Discipline and Experience, 1930

10 Structure of the Leningrad Physico-Technical

Institute, 1935

\section{TABLES IN APPENDIXES}

Appendix A: The History and Politics of Soviet Physics

A. 1 Membership in the RFKhO, 1890-1916

A. 2 Scholars Receiving TsEKUBU Ration, Total Number, 1919-1923

A. 3 Scholars Receiving Ration, by Discipline, 1921-1925 332

A. 4 All-Union Conferences in Physics, 1931-1939 
A. 5 Nobel Prizes for Soviet Physicists

333

A. 6 Number of Scientific Workers in RSFSR, By Discipline and Party Membership, 1923-1929

Appendix B: The Leningrad PhysicoTeChNical Institute

B. 1 Permanent Staff of LFTI (Excluding Sverkhstatnye), 1922-1926

B. 2 Graduates of Physico-Mechanical Department of LPI, 1922-1930, by Specialty and Place of Work

B. 3 Academic Council Meetings of LFTI, 1918-1926

B. 4 Institutes Created from the Leningrad PhysicoTechnical Institute

B. 5 Academicians and Corresponding Members of the Academy of Sciences Who Have Worked at the Leningrad Physico-Technical Institute as of 1978

B. 6 Party Membership of LFTI Workers, July 1926

B. 7 List of Members of LFTI Party Kollektiv, July 1926

B. 8 Planned Staff of LFTI, by Position, Discipline and Party Membership, 1930-1932

B. 9 Aspirantura at the Leningrad Physico-Technical Institute, 1934-1935

B. 10 Budget of Leningrad Physico-Technical Institute, First Five-Year Plan (1928-1932)

B. 11 Staff and Salaries of Leningrad Physico-Technical Institute, 1928-1932

\section{Appendix C: Publication}

C. 1 Publication of Physics Journals in Russia, 1917-1923, by Volume and Number of Issues

C. 2 Institutional Affiliation of ZhRFKhO Authors, 19231930, by Number of Articles and Percentage

C. 3 Institutional Affiliation of ZPF Authors, 1924-1930, by Number of Articles and Percentage

C. 4 Articles Written by Soviet Scholars in Zeitschrift für Physik, 1-103 (1920-1936) 
C. 5 Articles Published in ZETF, by Institute and City, 1931-1939

C. 6 Articles Published in ZTF, by Institute and City, 1931-1939 
